\title{
Higher Education Quality Management in Virtual Space of a Regional Higher Educational Institution
}

\author{
Oleg M. Barbakov \\ Marina L. Belonozhko \\ Svetlana S. Siteva \\ Tyumen State Oil and Gas University, Russian Federation \\ Email:mlb@inbox.ru
}

\section{Doi:10.5901/mjss.2015.v6n3s5p249}

\section{Abstract}

Nowadays it becomes highly urgent to promote educational services of a higher educational institution since its specialization is of great importance for the economy of a province. This is especially true for the oil and gas university, which trains specialists for oil and gas industry, i.e. the pillar of the Tyumen regional economy. The specific character of the geography of Russia diversity of climatic conditions, great area, also requires specific ways of training, such as distance learning and diversity of programs and syllabi. The article provides a substantiation of the methodology for social experiment in virtual space, which allows identifying the main alternative in the formulation and resolution of administrative tasks on issues of quality management in higher education in the regional higher educational institution by means of new automated information technologies; by choosing the most effective ones and introducing the results of the management into the real life practice of modern society. The authors suggest their version of use of the new technology of pattern recognition in the formulation and solution of the problem of increase in quality of education in the regional higher educational institution and in the creation of informational sociological proving grounds as an informational base when carrying out the experiment with the quality of education in virtual space.

Keywords: education quality, informational sociological proving grounds, pattern recognition, administrative tasks, virtual space, oil and gas university

\section{Introduction}

Under modern conditions, the educational system in Russia is being modified in compliance with the new requirements of the public life. The regulatory system is being changed and the educational process in higher educational institutions is becoming more sophisticated. One of the most important elements of this process is the quality of education, which is becoming increasingly significant with regard to innovation processes in regional higher education, such as the integration into national educational system, which, in turn, enters into the world educational space during the process of globalization of education (Robertson, 1995).

Today, higher education is of great importance in all spheres of life of society and the individual: in the government, in industry, services and other areas. That is why in recent years the issues of quality take a central place in the discussions on higher education, especially at the regional level.

Education system to a greater extent than other social institutions is exposed to the impact of globalization. The basic principle of globalization is the mutual dependence and interdependence of the various processes taking place in the global community. This creates the need for mobile professionals, capable of interpreting creatively the information obtained in the different educational structures and to implement it in their professional activities. "It should be noted that in the world there are growing flows of interstate movement of professionals" (Rothschild \& White, 1993, p.27).

Thus, globalization - is, above all, the production and the concentration of intellectual resources in the wealthiest countries. Control of national systems of education and information therefore becomes essential both domestically and geopolitically. Modern flexible technologies require appropriate quality of the labor force and the globalization of technology necessitates the globalization of educational space, convergence of curricula and content of academic disciplines in universities around the world. A modern professional is required to have the ability of quickly re-learning, of acquiring knowledge independently. Knowledge in the field of new information technologies, methods of optimization of 
economic processes, managerial decision making, financial and management innovation, quality control and logistics are becoming particularly important (Smolicz, 1996).

Naturally, this will require a significant restructuring of the entire infrastructure of the educational system in Russia and its regions. We need to be prepared to these processes today. Globalization of world education is a long and complicated process that is associated with a number of limiting factors (language barrier, historical traditions, different cultures, ideologies, religions, etc.). However, this process is already underway (Barbakov, 2007).

Due to the globalization, the process of integration of the educational system of Russia in the international educational community requires making necessary for the universities in the regions to include active non-traditional university activities among which the actions aimed at improving the quality of education and professionalism of the teaching staff of universities take one of the main places.

In this respect, approaches to determining the quality of teaching change substantially. A modern world-class regional higher educational institution needs a professor who changed his/her structure of priorities of professional and moral qualities as a result of the educational innovations. This should be a subject capable of self-determination and selfdevelopment in an ever-changing patterns of learning, the subject that receives the professional designation as a critical imperative of his/her life activity, the subject, capable of continuous improvement of his/her skills, etc. (Belonozhko et. al., 2013). The set of criteria and indicators for assessing the quality of education in regional higher educational institutions varies in quite a wide range that gives the possibility to use new information technologies in solving problems of selection of the bases for quality assessment of education in the higher educational institutions, when the executive making a decision has to deal primarily with the so-called semi-structured tasks, containing quantitative and qualitative problems. Sometimes the qualitative, little-known and uncertain aspects tend to dominate. Such assignments are based on the initial data, difficult to formalize. "The structure of their solution is not clearly identified; in each case it has its peculiarities. In such situations the executive acts unpredictably, using creative, heuristic and intuitive components of intellectual work, as well as mental analysis of the presented information and selection of variants of decisions" (Joseph et. al., 2005, p.79). For processing and analysis of semistructured information in formulating and solving management problems in the oil and gas university it is offered to use the new technology of pattern recognition. The article presents the author's justification for this.

\section{Indicators in the New Technology of Pattern Recognition in Evaluating the Education Quality}

Analysis of a great amount of literature on the identified issues of organizing control of innovative educational technologies on the virtual space has shown its lack of elaboration in theoretical terms and in terms of its practical implementation. Individual elements were considered by scientists - theorists and practitioners, for example, A.A. Laptev, V.Y. Raitsin and others, who proposed basic principles of mathematical modeling of social processes. O.F. Shabarov substantiated the theory and practice of computer simulation in the social and political sphere, Smerantsev G. articulated basis for the use of simulation for the management of social processes, while O.F. Balatsky, D.V. Belyshev, V.I. Gurman and a number of other scholars proposed basic principles of modeling such large scale social objects as social, ecological and economic systems (see Barbakov \& Kiselyov, 2012).

In all of these studies, there are elements of control and of automation of its organization, but the control of innovative educational technologies as a core element in a social experiment on the internet is not a subject of intense study of the scientific community yet.

Proceeding from the above, we can conclude that a method to control the virtual space of the performance of different kind of innovation in higher education is still not developed, which led to the choice of the problem as a research topic.

Certain stages of solving semi-structured problems can be transferred into computer virtual space. It seems appropriate to apply the new technology of pattern recognition. Novosibirsk school of geologists - mathematicians and theorists - suggested using the following methodology of pattern recognition at solving semi-structured problems: experiment; building interpretation models on the computer; economic evaluation of the solution effectiveness (Langenberg, 1994). They suggested applying the given technology in realization of these models when assessing the quality of regional higher education, changing the order of stages, creating informational sociological proving grounds, on which the formulation and solution of the problem of assessment of education quality in the oil and gas higher educational institution will be implemented. The basis of such proving grounds will be databases, with the help of which an analysis and social experiment in virtual space will be accomplished.

Virtual informational sociological proving grounds are the ways of description and research of the objects, revealing regularities of interaction of their properties, formalization of which enables creation of the basis of mathematical models 
for making administrative decisions. The object of the author's study is quality of higher education in the regional higher educational institution represented by, according to V.V. Mayer, fundamental characteristics of education, defined by the complex of factors, conditions and resources such as educational and methodological environment, resource base, the ability of the personnel, motivation and qualification of students, financial support, information services and other base elements of the educational activity of the oil and gas higher educational institution, each of which is implemented in their system of specific criteria and indicators (Mayer, 2006).

In the scientific literature, many approaches to arrangement of education quality indicators are represented. Zagvyazinskiy (1990) combines the education quality indicators in the following five directions: Knowledge and skills; Personality's development; Competence of the subjects of education: teachers and executives; A school's prestige in the society; and Negative effects of the educational process.

Davydova (2004) identified the components of the quality of education, each characterized by its own set of indicators:

- Requirement-target component, whose set of indicators determines needs, motivation, socially significant goals of various parties of educational process;

- Programmatically meaningful component, where the indicators determine the main educational program content;

- Procedural-technological component in which the indicators display the activity approach to education quality and formation of methods of educational activity;

- Social and personal component, including a set of indicators of development and education of the person.

Episheva (2001) in her own way determines components of the quality of education by analyzing the quality of education within the framework of: a) the quality of students' knowledge (depth, breadth, regularity, systematic approach, efficiency, flexibility, generality and concretization); b) the level of acquisition of the studied material (perception, memory and recall of knowledge and ways of life on the model, the assimilation of ways to acquire and apply knowledge, readiness for creative application of knowledge and ways of life); c) the level of substantive solutions and training (including professional content) tasks; d) level of mastery of the methods of independent learning activity of students.

In fact, in the complexes of the components of education quality, different scientists always present social goals and motivation of the subjects of education, their competence, level and quality of mastering educational programs, certain types of educational process. This is the basis for the competence approach used in the universities today.

Generalization and analysis of a variety of approaches to quality of education in a higher educational institution allowed V.V. Mayer to build a model of education quality management system at oil and gas university, which includes horizontal - essential and accessory, vertical and providing processes (Mayer, 2006).

In the framework of this model, it is possible to identify a set of key indicators of quality of education in the higher educational institution as the basis of the information base on informational sociological proving grounds, the creation of which is the initial stage of development of the automated system of quality management of education in the oil and gas higher educational institution. The analysis of components of the quality of education allowed the authors to identify a set of core indicators characterizing these components as the ground of the information base on the information and sociological landfills, the creation of which is the initial step in the development of automated control system for the quality of education in oil and gas university. Social experiments can be carried out on such virtual proving grounds. This will help to simulate the stages of quality management education in high school up to management decision-making and monitoring their effectiveness and efficiency, which are performance indicators of accreditation of the university.

\section{Methodological Substantiation of Assessing the Quality Of Higher Education}

On such virtual proving grounds, it is possible to accomplish social experiments, during which the stages of education quality management will be simulated until the decision-making and monitoring of their efficiency and effectiveness performance of accreditation indicators of the oil and gas university.

Basic indicators of quality of education in the oil and gas higher educational institution are identified within the framework of the basic processes of University activity. For example, the quality of the educational process is determined by the following: indicators characterizing training for entering the higher educational institution, the Unified State Examination score, etc.; information on all ongoing basic educational programs; the quantity and quality of textbooks and manuals; the main characteristics of the training of a competent specialist primarily for regional labor market; characteristics of the innovative methods used in the educational process; information about the faculty; indicators of the teachers training process, i.e. advanced professional training of teachers, etc. 
For the scientific process the characteristic indicators are as follows: the criteria of teachers' research activity, for example, information about the monographs, scientific activity of research institutes involved in the structure of the higher educational institution, information on scientific-research works etc.; indicators of quality of training of scientific workers via magistracy, postgraduate study, and doctoral studies; the criteria of guidance of students' research work and others.

The quality criteria of the accessory processes are as follows: indicators of vocational guidance and selection of applicants, the extra-curricular work and methodological activity, scientific and research activity of students, introduction of information and communication technologies, additional educational services and others (Budyanskiy, 1992)

Each of the quality criteria of the institution's activity can be expressed as a set of properties characterizing them. Data sets of the criteria - indicators and properties that determine them have become the main content of the informational sociological proving ground (Mamraev \& Akimbayeva, 2010).

In the process of organization of the experiment in virtual space, necessary initial information was defined in the form of education quality criteria in the oil and gas higher educational institution in the existing data bank and additional information gathering, its formalization and input into the data bank. The creation of the experiment information database required the use of various methods of gathering the information necessary for the solution of management problems. One of these methods is that of sociological research. Then the proving ground was formed, where the management task was posed.

When forming the informational sociological proving grounds and conducting experiments primarily there were identified the objectives of management activities, general global and particular intermediate ones, and specified managerial tasks to be solved for the achievement of the set objectives. In the framework of the construction of the automated system of quality management of education in the regional higher educational institution the goal of the experiments is the improvement of the quality of education and determination of the quantitative and qualitative content of the optimal complex of its criteria and indicators.

On the informational sociological proving ground within the designated purpose there were allocated objects, and given their description i.e. the interpretation model was formed on the computer. The created computing base (algorithms, programming language, and type of computer equipment) has become data ware of task solution at this stage.

The model of the experiment in virtual space, suggested by the authors, comprised the following: on the proving ground they defined the so-called direct property by a special scale -the studied objects of the education quality in the higher educational institution: different levels of education quality by a group of institution's processes from low to high. On the proving ground they have established the links between direct or target property (groups of different levels of quality of education) and a set of indirect indicators characterizing each level of the quality of education, which comprise the highest level of quality - the desirable state of the object of the experiment.

The indicators, quantitatively or qualitatively describing the level of education quality for all groups of the higher educational institution's processes, called 'indirect properties' were selected by the authors at the stage of formulation administrative tasks in the formation of informational sociological proving ground according to the results of the inspection of the regional higher educational institution. The following indicators were used as the most typical ones affecting the direct property - the quality of education:

1. Provision of the educational process (educational programs, curricula, programs of disciplines).

2. Quality of training of students (results of defend of graduation projects).

3. Structure of training within basic educational programs (number of implemented basic educational programs, student body).

4. Possibility of further education on educational programs.

- Postgraduate and doctoral studies (the number of specialties, the number of postgraduate students per 100 students of the given student body, the number of postgraduate students, defending theses).

- Dissertation councils (the number of specialties, the number of Councils).

- Additional educational programs.

5. Information and library support of the educational process (the library stock, the number of seats in the library, the availability of use etc.)

6. The level of informatization of the higher educational institution (local networks, the Internet, hardware and software, their quantitative characteristics).

7. Research works (the number of branches of science, in the framework of which the research works are accomplished, the volume of fundamental and applied research, the volume of research per faculty unit, scientific schools of the institution).

8. Methodological work (number of textbooks, manuals, monographs per 100 teaching staff). 
9. Faculty (the number of teachers with degrees and titles, the number of doctors of Sciences (professors).

10. Pre-university training and selection of applicants (career guidance).

11. The demand for graduates (applications from employers, the number of employed graduates).

12. Social structure and support for students (social security, presence of centers of public catering, health centers, dormitories).

13. Material and technical basis of the University (the total area of buildings, equipment).

14. Financial condition (stability) of the University (cost of fixed assets, revenue and expense structure).

15. This intramural mechanism of quality guarantees of education (availability and effectiveness of intramural quality management system of education) (Lawn, 2001).

Informational sociological proving ground represents the patterns of the first approximation of direct property: the level of quality of higher education in the space of indirect properties - indicators.

Computer allows designing direct property dependence, both from separate indicators and their combinations. Here various combinations affect the direct property differently. For example, in the space of such indicators as the number of profiles of implemented basic educational programs and the number of post-graduate specialties, there form different patterns of direct property (the level of quality of education) - the fields, each of which possesses a number of points. The fields, from low to high education quality in the higher educational institution, form. Naturally, it is very difficult to allocate objects of direct property in the subspace of two indicators; it could be done easier in the space of three, four or more indicators. This is only possible using the new technology of pattern recognition, when in the space of indicators there form patterns of the first approximation of the level of quality of education in the regional higher educational institution, representing fields in the space of indirect properties, each of which has its own value of direct property. The patterns intersect by different values of indirect properties; inside the patterns, there may be their own sub-patterns: grouping objects -fields within larger ones. In the process of formulation of an administrative task, they determine an optimal complex of the most informative indirect properties in which space the patterns of direct properties are clearly recognized (Dougherty, 2012).

\section{Informational Sociological Proving Ground}

Every time when formulating and solving an administrative task there forms the so-called informational sociological proving ground, which contains well-known objects: patterns and sub-patterns, for each of which the typical direct target property and the set of indirect properties, are allocated, and they characterize some qualitative aspects of these objects. And each direct property or its interval possesses its own set of values of indirect properties.

Besides, a rational complex of indirect properties, i.e. the properties most clearly defining the object, is distinguished. At calculation such properties have the highest informativity; when distinguishing patterns and sub-patterns they make the highest contribution. Other indirect properties with low informativity have a little impact on the pattern formation, therefore they are not regarded. All the calculations are carried out only with the participation of highinformative properties, and their contribution in the calculations is regulated by corresponding coefficients of informativity. The entire proving ground represents a set of patterns and sub-patterns of quality of education in the higher educational institution, which is used at the stage of the administrative task solution.

At the stage of task solution, the objects of groups with different levels of education quality are reduced to groups with its high level by varying the ratio of indirect properties using the computational base of the proving ground. Such objects are compared with the patterns and sub-patterns of the proving ground via the field of indirect properties using a rational set of these properties, their individual informativity and the priority of combinations of indirect properties. The basis for such a comparison is a geometric approach in all subfields of indirect properties in accordance with the similarity of these objects with the nearest objects of patterns and sub-patterns of the proving ground; and by varying the ratio of indirect properties the maximum measure of similarity with the pattern and sub-patterns of the group with a high level of education quality is selected.

Thus, every time when solving any administrative task, first the formulation of this task on the proving ground takes place, and then the solution of such a problem in the field of research. Making administrative decisions is automated and is accomplished by selecting the most effective solutions from a set of options identified at a training ground in the process of conducting an experiment in virtual space in which a knowledge base is created, the base of alternative ways of solution of administrative tasks, taking into account different indicators of a management object, environmental conditions in functioning of the investigated and managed process. If none of the options of the base of alternatives meets the degree of accuracy of achievement, an expert-executive enters the process of management.

As a result of task setting on the informational sociological proving ground a set of patterns of the direct target 
property is formed. Each time a new formulation of the task is carried out and new patterns are created, which gives an opportunity to form an entire database of different patterns, which can be used for solving various administrative tasks further on. Informational sociological proving ground with such a base is, undoubtedly, a new step in formulation and solution of the tasks in simulation of the processes of improving the quality of education at higher educational institutions, when conducting social forecasting and social experiments in the information space of the oil and gas university. The selection of patterns of direct target property is automated, i.e. making an administrative decision about predicting this property with the sought-for objects and bringing them to a certain pattern.

\section{Conclusion}

The process of improving the quality of education at the oil and gas university and its management system is transferred into the informational space, the so-called virtual reality, which is an illusory world artificially created with the help of technical imitation means called virtual reality systems, which man is plunged in and interacts with. This methodology of conducting the social experiment of education quality management in the oil and gas higher educational institution in virtual space identifies the directions of development of social objects and phenomena on simulated models in the information space. Traditional methods of improving the quality of education often fix targets universities have to achieve, Although they do not evaluate the results, if these figures differ from the designated. The new technology of pattern recognition within the formulation and solution of managerial tasks on the virtual space makes it possible to define a set of alternative ways to improve the quality of higher education and choose the most effective for the specific conditions of each individual institution.

\section{References}

Barbakov, O. M. (2007). Formulation of the problems of control on the internet of performance of innovative technologies in the higher education system of the Tyumen region. News from Higher Educational Institutions. Sociology. Economics. Politics, 2, 112-117.

Barbakov, O. M., \& Kiselyov, V. G. (2012). Methodology of Carrying Out Social Experiments in Virtual Space. Tyumen State University Herald, 8, 201-206.

Belonozhko, M. L, Silin, A. N., \& Gabysheva, L. K. (2013). On the results of implementing the requirements of the GEF in preparing managers. Bulletin of University, 5, 159-162.

Budyanskiy, Y. A. (1992). Geological Interpretation of Complex Geophysical Data. Moscow: Nedra.

Davydova, L. N. (2004). The Components of Education Quality. Bulletin of Higher School, 11, 34-39.

Dougherty, G. (2012). Pattern Recognition and Classification. New York. [Online] Available: http://extras.springer.com.html_(February 11, 2015).

Episheva, O. B. (2001). Activity Approach to Creation of the Concept of Education Quality Management. Proceedings of the 4th Int. Scientific Conference "Quality of education. Achievements. Issues". Novosibirsk: NSTU.

Joseph, M., Yakhou., M., \& Stone, G. (2005). An educational institution's quest for service quality: customers' perspective. Quality Assurance in Education, 13(1), 66-82.

Langenberg, D. N. (1994). Information technology and the university: Integration strategies for the 21st century. J. Amer. Soc. Inform. Science, 45 (5), 323-325.

Lawn, M. (2001). Borderless Education: Imagining a European Education Space in a Time of Brands and Networks. Discourse: Studies in the Cultural Politics of Education, 22 (2), 173-184.

Mamraev, B., \& Akimbayeva, A. (2010). Priority areas for science progress in Kazakhstan. International journal of applied and fundamental research, 4, 78-83.

Mayer, V.V. (2006). Sociological Concept of Forming the System of Quality Management in Higher Education. Tyumen.

Robertson, R. (1995). Globalization: Social Theory and Global Culture. London.

Rothschild, M., \& White, L.J. (1993). The university in the marketplace: some insights and some puzzles. In C. T. Clotfelter \& M. Rothschild (Eds.) Studies of supply and demand in higher education (pp. 11-42). Chicago: University of Chicago Press.

Smolicz, J. J. (1996). Education For a Global Society. Education and Society, 14(2), 83-87.

Zagvyazinskiy, V.I. (1990). Indirect Impact of Methodology on Practice. Journal Soviet Pedagogy, 3, 78-85. 